\title{
Article \\ Evaluation of Clinical and Immune Responses in Recovered Children with Mild COVID-19
}

\author{
Xiaodong Tian ${ }^{1,2,+}$, Zhihua Bai ${ }^{1,3,+}$, Ying Cao ${ }^{4}$ (), Haizhou Liu ${ }^{4}$, Di Liu ${ }^{4, *}$, Wenjun Liu ${ }^{1,3, *}$ and Jing Li ${ }^{1,3, *(D)}$ \\ 1 CAS Key Laboratory of Pathogenic Microbiology and Immunology, Institute of Microbiology, \\ Chinese Academy of Sciences, Beijing 100101, China; tienhsiaotung@foxmail.com (X.T.); \\ baizhihua19@mails.ucas.ac.cn (Z.B.) \\ 2 School of Life Sciences, University of Science and Technology of China, Hefei 230026, China \\ 3 Savaid Medical School, University of the Chinese Academy of Sciences, Beijing 100049, China \\ 4 Computational Virology Group, Center for Bacteria and Virus Resources and Application, \\ Wuhan Institute of Virology, Chinese Academy of Sciences, Wuhan 430071, China; \\ caoyingor@163.com (Y.C.); liuhz@wh.iov.cn (H.L.) \\ * Correspondence: liud@wh.iov.cn (D.L.); liuwj@im.ac.cn (W.L.); lj418@163.com (J.L.) \\ $\dagger$ These authors contributed equally to this work.
}

Citation: Tian, X.; Bai, Z.; Cao, Y.; Liu, H.; Liu, D.; Liu, W.; Li, J. Evaluation of Clinical and Immune Responses in Recovered Children with Mild COVID-19. Viruses 2022, 14, 85. https://doi.org/10.3390/v14010085

Academic Editors: Concetta Castilletti, Luisa Barzon and Francesca Colavita

Received: 8 December 2021

Accepted: 1 January 2022

Published: 4 January 2022

Publisher's Note: MDPI stays neutral with regard to jurisdictional claims in published maps and institutional affiliations.

Copyright: (c) 2022 by the authors. Licensee MDPI, Basel, Switzerland. This article is an open access article distributed under the terms and conditions of the Creative Commons Attribution (CC BY) license (https:// creativecommons.org/licenses/by/ $4.0 /)$.

\begin{abstract}
The coronavirus disease 2019 (COVID-19) has spread globally and variants continue to emerge, with children are accounting for a growing share of COVID-19 cases. However, the establishment of immune memory and the long-term health consequences in asymptomatic or mildly symptomatic children after severe acute respiratory syndrome coronavirus 2 infection are not fully understood. We collected clinical data and whole blood samples from discharged children for 6-8 months after symptom onset among 0-to-14-year-old children. Representative inflammation signs returned to normal in all age ranges. The infants and young children ( $0-4$ years old) had lung lesions that persisted for 6-8 months and were less responsive for antigen-specific IgG secretion. In the 5-to-14-year-old group, lung imaging abnormalities gradually recovered, and the IgG-specific antibody response was strongest. In addition, we found a robust $\operatorname{IgM}^{+}$memory B cell response in all age. Memory T cells specific for the spike or nucleocapsid protein were generated, with no significant difference in IFN- $\gamma$ response among all ages. Our study highlights that although lung lesions caused by COVID-19 can last for at least 6-8 months in infants and young children, most children have detectable residual neutralizing antibodies and specific cellular immune responses at this stage.
\end{abstract}

Keywords: SARS-CoV-2; recovered children; clinical; immune responses; mild COVID-19

\section{Introduction}

Coronavirus disease 2019 (COVID-19) caused by severe acute respiratory syndrome coronavirus 2 (SARS-CoV-2) is wreaking havoc worldwide [1-3]. Detecting the effectiveness and durability of the immunologic response to SARS-CoV-2 in convalescent persons will allow better assessment of the risk of reinfection and formulation of vaccination strategies. SARS-CoV-2 elicits the production of broadly directed and functionally replete memory $T$ cells with different functions $[4,5]$. Specific antibodies capable of neutralizing the virus persist for at least 9 months in most recovered individuals, and antigen-specific $\mathrm{IgG}^{+} \mathrm{mem}^{-}$ ory B cells increase in number during recovery [6,7]. Importantly, memory lymphocytes from COVID-19 patients display functional responsiveness that may contribute to antiviral resistance upon reinfection [8]. The available data have demonstrated that both humoral and cellular immunity are involved in COVID-19 recovery and may protect against recurrent episodes of severe COVID-19 $[9,10]$. Nevertheless, it is still worth emphasizing that rather than a definitive picture, the understanding of adaptive immunity to SARS-CoV-2 is still evolving.

From the quotable data, children constitute a growing share of COVID-19 cases. More than 3.87 million children (0-15 years old) have tested positive since the outbreak began, 
accounting for approximately $11.6 \%$ of all cases in the United States (https:/ / covid.cdc. gov / covid-data-tracker/, accessed on 29 November 2021). Epidemiological investigations and clinical monitoring indicate that the majority of infected children tend to develop mild or asymptomatic symptoms [11-14]. However, there is still little information about the magnitude or stability of the immune response in this large population and whether the development of immune memory varies depending on the age of the individual or the severity of the disease.

In response to this need, we recruited 31 convalescent children who had asymptomatic or mildly symptomatic COVID-19 between 27 January and 11 March 2020 and described the recovery situation after discharge at the 6-8-month revisit. We collected serum and PBMCs, focused on evaluating the dynamics of specific antibodies and measured the antigenspecific memory B cell and T cell responses for up to 6-8 months after acute infection. We also analyzed the correlation between the humoral and cellular immune responses and individual age at infection. Knowledge of the durability of the initial immune response and the protective capacity of immune memory will provide references for the protection for children and provide a basis for future vaccine development for children.

\section{Methods and Materials}

\subsection{Ethics Statement}

The analytical samples and protocols used in this study were approved by the Ethics Committee of Wuhan Children's Hospital and Wuhan Maternal and Child Health Hospital (Approval Code: WHCH2020003, Approval Date: 4 February 2020). A written statement that the formal consent of the parent/guardian has been obtained and that the parent/guardian is informed that the study is anonymous. All experiments involving SARS-CoV-2 strains were conducted in a biosafety level 2 (BSL2) laboratory, were approved by the Institute of Microbiology, Chinese Academy of Sciences (IMCAS), and complied with all relevant ethical regulations regarding human research.

The HEK-293T cells line was provided by ATCC CRL-11268. The 293T-ACE2 cell line, the pLenti-GFP lentiviral reporter, plasmids psPAX2, and codon-optimized cDNA encoding SARS-CoV-2 S glycoprotein (QHU36824.1) were obtained from Dr. Zhao Zhendong, Institute of Pathogenic Biology, Chinese Academy of Medical Sciences [15].

\subsection{Study Design}

Serum samples $(n=31)$ and PBMCs $(n=21)$ of 31 recovered children $(R C)$ were collected 6-8 months after initial diagnosis. Serum samples $(\mathrm{n}=22)$ and PBMCs $(\mathrm{n}=17)$ were isolated from 22 age-matched healthy controls $(\mathrm{HC})$. Anti-Spike protein antibody and anti-Nucleocapsid protein antibody (IgG and IgM) levels were measured by ELISA to assess serum antibody levels during recovery, and T/B cells, NK cells and monocytes were further divided by flow cytometry to determine the memory subtypes of $\mathrm{T}$ cells and $B$ cells and to interpret the effects of SARS-CoV-2 infection on the immune system. In addition, to evaluate the functional status of $\mathrm{T}$ cell and $\mathrm{B}$ cell populations during recovery, PBMCs were stimulated in vitro to detect the secretion levels of cytokines (IFN- $\gamma$ ) and antibodies (IgG, IgM, and IgA). A comprehensive analysis of the above results revealed the characteristics of adaptive immune memory in children who recovered from COVID-19 and its correspondence with clinical signs.

\subsection{Collection of Clinical Samples from Children}

The samples were collected from recovered children in Wuhan Children's Hospital, with a mean \pm standard deviation (STDEV) and age range of $5.48 \pm 4.48$ and $0.1-14$, respectively. In the healthy control group, the mean \pm STDEV and age ranges were $5.09 \pm 3.54$ and $0.58-12$, respectively. The patient infections were confirmed by one or more RT-PCR tests. The clinical diagnosis was based on the Diagnosis, Treatment and Prevention of 2019 Novel Coronavirus Infection in Children: Experts' Consensus Statement (Third Edition). Asymptomatic infected persons were defined as those who had no self-perceived or 
clinically identifiable symptoms or signs of upper respiratory tract infection, namely, pharyngeal congestion, sore throat and fever, or abnormalities on imaging examination. Mild infection was defined as a child with pneumonia with radiological respiratory symptoms.

Whole blood was diluted with an equal amount of PBS and transferred to a SepMate tube (STEMCELL Technologies). Serum, platelets, granulocytes, and red blood cells were isolated from PBMCs using Lymphoprep ${ }^{\mathrm{TM}}$ (STEMCELL Technologies) and centrifuged at $1000 \times g$ at $20^{\circ} \mathrm{C}$ for $10 \mathrm{~min}$. The PBMCs were transferred and washed with PBS and centrifuged at $350 \times g$ for $5 \mathrm{~min}$ at room temperature. PBMCs were resuspended and eventually stored in liquid nitrogen until use. The serum was precipitated with coagulant, inactivated, and stored at $-80^{\circ} \mathrm{C}$ before use.

\subsection{Cell Culture}

The frozen PBMCs were thawed at $37^{\circ} \mathrm{C}$ and prepared in Roswell Park Memorial Institute (RPMI) 1640 medium containing nuclease (final concentration $\geq 50 \mathrm{U} / \mathrm{mL}$ ) for $30 \mathrm{~min}$. After centrifugation at $1000 \times \mathrm{g}$ for $5 \mathrm{~min}$ at room temperature, the cells were washed twice with RPMI 1640 medium. Finally, the nuclei of PBMCs were stained with Acridine Orange/Propyl Iodide (AO/PI) dye, and the ratio of dead cells to alive cells was calculated in the fluorescence field. In the fluorescence field, the nuclei of dead cells were red and those of living cells were green.

The HEK-293T cell line and 293T-ACE2 cell line were cultured in Dulbecco's modified Eagle's medium (DMEM) containing 10\% fetal bovine serum (Gibco) and $100 \mu \mathrm{g} / \mathrm{mL}$ penicillin-streptomycin (Gibco) in $5 \% \mathrm{CO}_{2}$ at $37^{\circ} \mathrm{C}$.

\subsection{ELISA}

Binding plates (Costar) were coated with $100 \mathrm{ng} /$ well Spike protein or Nucleocapsid protein (SinoBiological) at $4{ }^{\circ} \mathrm{C}$ overnight. The plates were blocked with $4 \%$ bovine serum albumin (BSA) for $90 \mathrm{~min}$. After blocking, $50 \mu \mathrm{L}$ of serum dilution was added to each well and incubated at $37^{\circ} \mathrm{C}$ for $1 \mathrm{~h}$. The plates were washed with PBS containing $0.05 \%$ Tween-20. Enzyme-labeled goat anti-human IgG-Fc or enzyme-labeled goat anti-human IgM-Fc was added as the secondary antibody. After incubation for $45 \mathrm{~min}$, the plates were washed, $100 \mu \mathrm{L}$ of 3,3',5,5'-tetramethylbenzidine (TMB) substrate was added, and then 100 $\mu \mathrm{L}$ of $2 \mathrm{~mol} / \mathrm{L} \mathrm{H}_{2} \mathrm{SO}_{4}$ was added to stop the reaction. The microplates were read using a microplate reader (Multiskan FC, Thermo Scientific) at $450 \mathrm{~nm}$. The mean HC area under the curve (AUC) value + 3SD was used as the cutoff value to determine positive serum samples [6].

\subsection{Pseudovirus Neutralization Assays (PNT ${ }_{50}$ )}

Serum neutralizing antibodies (NAbs) in children with mild COVID-19 were detected by $\mathrm{PNT}_{50}$ assays, as described previously [15]. 293T cells were cotransfected with psPAX2, plenti-GFP and Spike protein to obtain pseudoviruses. 293T-ACE2 cells were seeded into 96-well plates at a density of $5 \times 10^{4}$ cells/well $24 \mathrm{~h}$ before infection. The diluent was mixed with a certain amount of pseudovirus, neutralized for $1 \mathrm{~h}$, added to a 96-well plate, and incubated at $37^{\circ} \mathrm{C}$ for $48 \mathrm{~h}$. The fate of the cells was monitored with high sensitivity using luciferase-based gene reporters (Beyotime). Finally, the semineutralization concentration was calculated by fitting the four-parameter curves according to the fluorescence values of different dilutions.

\subsection{Flow Cytometry and Antibodies}

PBMCs were used for cell composition analysis. Cells were stained with appropriate antibody-fluorophore conjugates in cold fluorescence-activated cell sorting (FACS) buffer at $4{ }^{\circ} \mathrm{C}$ for $30 \mathrm{~min}$ after incubation with Fc Block (BD Biosciences) and analyzed on an ARIA II (BD Biosciences). Dead cells were excluded via viability dye (eBioscience) staining for $30 \mathrm{~min}$. Data were analyzed with FlowJo software (BD Biosciences). Those for lymphocyte populations (FSC-H and SSC-H), (SSC-A and SSC-H), and the selection of living 
leukocytes (Fixable Viability Dye-780- and CD45- PE-eflour610 ${ }^{+}$). After the exclusion of monocytes (CD14-eflour450 $)$ and NK cells (Cd56-PE-Cyanine ${ }^{+}$), T cells, memory T cells (CD3-eflour560 ${ }^{+}$CD4-FITC ${ }^{+} / \mathrm{CD} 8-\mathrm{PE}-\mathrm{Cyanine} 5^{+}, \mathrm{CCR}$-PE ${ }^{+}$, and CD45RA-APC ${ }^{+}$), $\mathrm{B}$ cells, and memory B cells (CD19-PerCP-Cyanine5.5 $5^{+}$and CD27-Super Bright $780^{+}$) were analyzed. All above antibodies were obtained from eBioscience

\subsection{ELISPOT}

According to the manufacturer's instructions, $50 \mu \mathrm{L}$ of a $70 \%$ ethanol/water solution was added to the precoated IFN- $\gamma$ board and incubated for $2 \mathrm{~min}$, the polyvinylidene fluoride membrane was activated at the bottom of the board, and the membrane was rinsed 5 times with sterile water. A total of 200,000 white blood cells were mixed with S or N protein $(10 \mu \mathrm{g} / \mathrm{mL})$. An anti-CD3 antibody was added as positive control. The boards were incubated for $48 \mathrm{~h}$ in $5 \% \mathrm{CO}_{2}$ at $37{ }^{\circ} \mathrm{C}$ and then removed. After washing, an HRPconjugated antibody and TMB substrate were added for color rendering. When obvious spots appeared, the entire plate was rinsed with deionized water to stop the reaction. During the ELISPOT assays, 0-1 points were observed for each well in the control group.

\subsection{FluoroSpot Assays}

According to the manufacturer's instructions, $\mathrm{S}$ or $\mathrm{N}$ protein was precoated on an IPFL plate as an antigen. The number of thawed PBMCs was adjusted and counted, and the cells were prestimulated with R848 and IL-2 in 48-well plates for $72 \mathrm{~h}$. Finally, the cells were transferred to plates coated with $S$ or $\mathrm{N}$ protein and incubated again for $24 \mathrm{~h}$. The plates were removed and washed, and a 1:500-diluted antibody mixture was added and incubated. The fluorescence enhancer was incubated at $50 \mu \mathrm{L} /$ well for $15 \mathrm{~min}$ at room temperature, and then the plates were washed and dried to obtain clearer fluorescence spots. Fluorescent spots were recorded with a Fluorescent Spot Reader (AID iSpot Spectrum, AID GmbH).

\subsection{Statistical Analysis}

The $\mathrm{t}$-distributed stochastic neighbor embedding (tSNE) dimension reduction analysis was used to visualize the molecular expression patterns on the labeled cell surface. All of the data are presented as the mean \pm standard error of the mean. Spearman rankcorrelation tests were used for correlation analysis ( $\rho)$, and the Mann-Whitney U-test was used to determined $p$ value to compare position measurements of the healthy children and recovered groups with questionable normality assumptions.

\section{Results}

\subsection{Clinical Characteristics of COVID-19 Convalescent Subjects}

To understand the long-term health consequences of COVID-19 in children, we collected and compared 31 patients' clinical information and data during the acute phase of infection and approximately 6-8 months after symptom onset. Detailed information is shown in Supplementary Table S1. Among all individuals, 18 patients experienced mild pneumonia (58\%), 11 patients presented with acute upper respiratory tract infection (AURI) $(36 \%)$, and 2 confirmed persons were asymptomatic (6\%). As shown in Table 1, in contrast with those in other age groups, most patients in the $0-4$-year-old group developed mild pneumonia (63\%). Furthermore, mild elevations in the levels of inflammatory markers such as C-reactive protein (CRP), procalcitonin (PCT), and D-dimer, a biomarker associated with COVID-19 disease severity, returned to the normal range at follow-up, as well as those of other serological markers of the patients (Supplementary Table S2).

We also observed lung tissue repair and respiratory function recovery. All patients completed both pulmonary function tests and chest CT imaging during the follow-up. The lung imaging abnormalities gradually improved over 6-8 months. In most patients, the proportions of ground-glass opacities decreased, and lung lesions were absorbed. However, patchy shadows were still seen in several cases. Additionally, pulmonary function tests showed no pulmonary dysfunction or mildly restrictive lesions (33\%) in the 5-9-year-old 
or 10-14-year-old age group, respectively. In the 0 -to-4-year-old age group, $13 \%$ of patients presented mild-to-moderate obstructive disease, and $25 \%$ of patients presented moderate obstructive disease (Supplementary Table S3). Overall, sequential follow-up evaluations at 6-8 months after COVID-19 onset demonstrated a vast improvement in symptoms and chest CT abnormalities over time, and the majority of study participants had functional recovery from COVID-19. However, we also found that some children, especially infants and young children, had lung lesions that persisted for 6-8 months.

Table 1. Clinical features of children recovered from mild COVID-19.

\begin{tabular}{|c|c|c|c|}
\hline Clinical Indicators & $\begin{array}{c}0-4 \text { Years Old } \\
(\%)\end{array}$ & $\begin{array}{c}\text { 5-9 Years Old } \\
(\%)\end{array}$ & $\begin{array}{c}\text { 10-14 Years Old } \\
(\%)\end{array}$ \\
\hline \multicolumn{4}{|l|}{ Clinical type } \\
\hline Asymptomatic & $1(6 \%)$ & $0(0 \%)$ & $1(17 \%)$ \\
\hline $\begin{array}{l}\text { Acute Upper Respiratory } \\
\text { Infection (AURI) }\end{array}$ & $5(31 \%)$ & $4(44 \%)$ & $2(33 \%)$ \\
\hline Mild pneumonia & $10(63 \%)$ & $5(56 \%)$ & $3(50 \%)$ \\
\hline \multicolumn{4}{|l|}{ Symptoms } \\
\hline Fever & $8(50 \%)$ & $4(44 \%)$ & $3(50 \%)$ \\
\hline Cough & $12(75 \%)$ & $4(44 \%)$ & $3(50 \%)$ \\
\hline Expectoration & $4(25 \%)$ & $1(13 \%)$ & $0(0 \%)$ \\
\hline Congestion & $2(13 \%)$ & $0(0 \%)$ & $0(0 \%)$ \\
\hline Excessive fatigue & $0(0 \%)$ & $0(0 \%)$ & $1(17 \%)$ \\
\hline \multicolumn{4}{|l|}{ CT findings (Initial diagnosis) } \\
\hline Normal & $6(38 \%)$ & $4(44 \%)$ & $3(50 \%)$ \\
\hline Ground-glass Opacity (GGO) & $7(44 \%)$ & $3(33 \%)$ & $2(33 \%)$ \\
\hline Patchy Shadow & $3(19 \%)$ & $2(22 \%)$ & $1(17 \%)$ \\
\hline \multicolumn{4}{|l|}{ Pneumonia } \\
\hline NA & $6(38 \%)$ & $4(44 \%)$ & $3(50 \%)$ \\
\hline Unilateral (Left) & $2(13 \%)$ & $0(0 \%)$ & $0(0 \%)$ \\
\hline Unilateral (Right) & $3(19 \%)$ & $3(33 \%)$ & $1(17 \%)$ \\
\hline Bilateral (Both) & $5(31 \%)$ & $2(22 \%)$ & $2(33 \%)$ \\
\hline \multicolumn{4}{|l|}{ CT findings (Follow-up visit) } \\
\hline Not Recovered & $8(50 \%)$ & $3(33 \%)$ & $0(0 \%)$ \\
\hline
\end{tabular}

No signs of meaningful complications were observed. The proportion shown in the table is that of the characteristic in the total population of the corresponding age group.

\subsection{SARS-CoV-2-Specific Antibodies Could Be Detected but Their Levels Waned in Recovered Children}

To evaluate the persistence of the antibody response in recovered children with mild COVID-19, the levels of SARS-CoV-2-specific spike or nucleocapsid antibodies in serum were detected. The results showed that recovered children who had all of these antibodies accounted for $3 \%$ of the total samples; those who were S-IgG ${ }^{+}$and $\mathrm{N}-\mathrm{IgG}^{+}$accounted for $38.7 \%$; those with only S-IgG ${ }^{+}$accounted for $48.4 \%$; and the percentage of those who were S-IgG-, S-IgM-, N-IgG ${ }^{+}$, and N-IgM+ ${ }^{+}$was $3 \%$. Specifically, the positive rates for specific antiS IgG and anti-N IgG were $81.3 \%$ and $43.8 \%$ in 0 -to-4-year-old children, $100 \%$ and $44.4 \%$ in 5-to-9-year-old children, and $83.3 \%$ and $50 \%$ in 10-to-14-year-old children, respectively (Supplementary Figure S1A,B). Furthermore, to compare the levels of residual antibodies in the antibody-positive population, the highest serum dilution $<200$ was defined as low, between 200 and 400 as moderate, and between 400 and 800 as high. Anti-S protein IgG levels were primarily maintained at a high level $(71.4 \%)$ and moderate level $(100 \%)$ in the 0-4-year-old and 5-9-year-old age groups, respectively, while those of anti-N protein IgG were maintained mainly at low levels in both groups ( $85.7 \%$ and $80.0 \%)$, respectively. In the 10-to-14-year-old age group, anti-S protein IgG was mainly maintained at a high level $(60.0 \%)$, and anti-N protein IgG was evenly distributed among the three titers (Figure 1A). The data regarding subsequent detection of serum NAb levels are shown in Supplementary Figure S1E. The examined children with PNT50 in the range of 160-640 accounted for the majority of all ages, with rates of $75 \%(0-4), 89 \%(5-9)$, and $83 \%(10-14)$, respectively (Figure 1B). Additionally, $97 \%$ of the recovered children had a negative conversion of anti-S 
IgM, and 94\% had a negative conversion of anti-N IgM. Only extremely low levels of anti-S and anti-N IgM were observed in a few individuals (Supplementary Figure S1C,D).

A

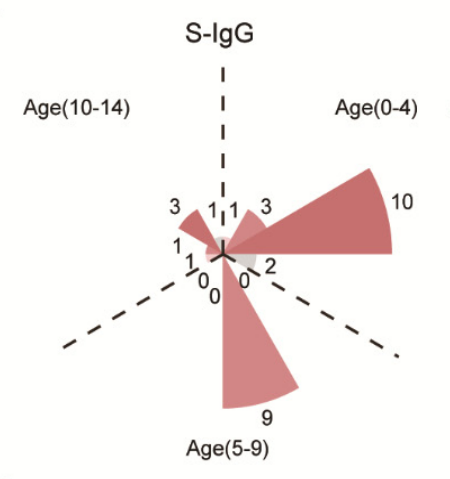

C
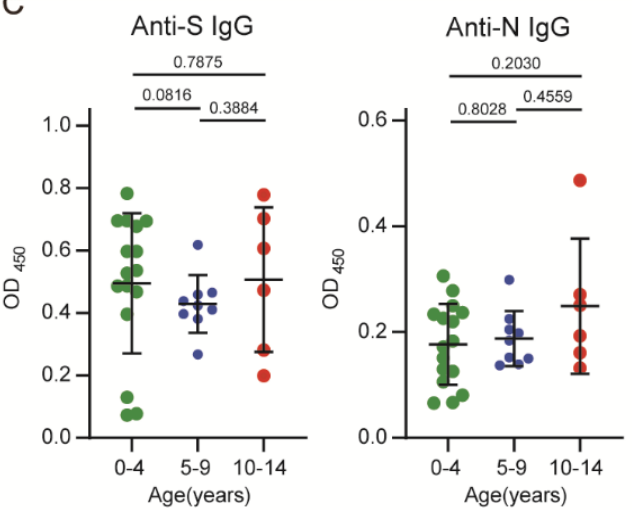

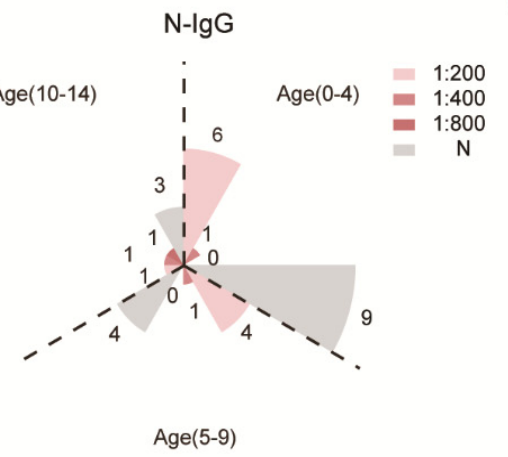

D

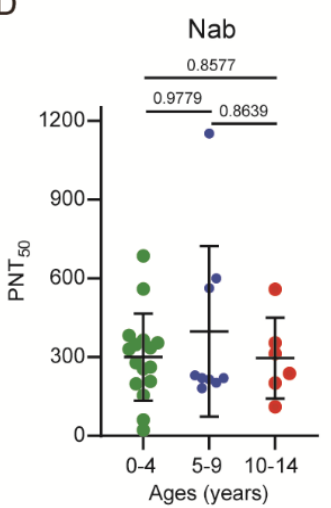

$E$
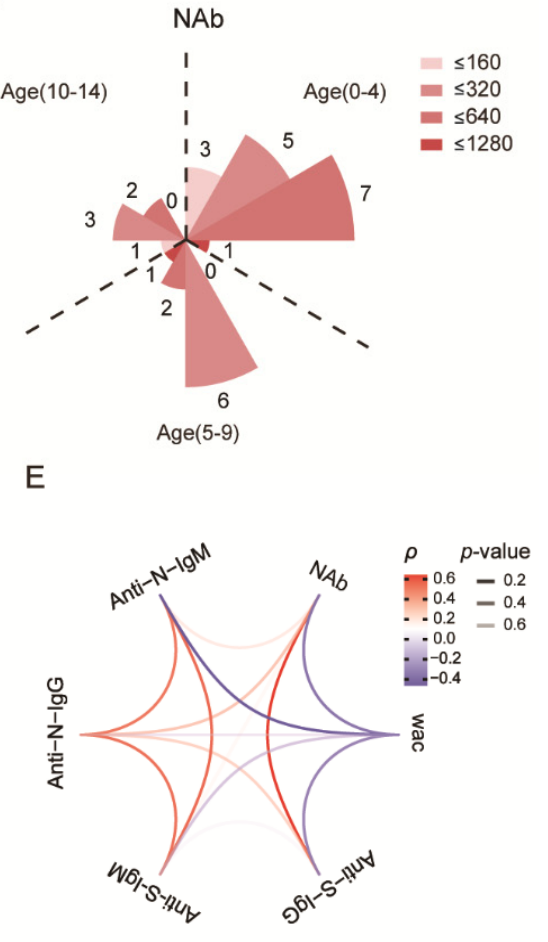

Figure 1. SARS-CoV-2-specific antibody response in children recovered for 6-8 months: (A) The absolute positive numbers of individuals with anti-S IgG and anti-N IgG antibody titers of undetected (N), 1:200 (low), 1:400 (moderate), and 1:800 (high). (B) Neutralizing antibody titers were determined according to different dilutions. (C,D) Differences in antibody levels between different age groups. (E) Correlations between different antibodies and the correlation between antibodies over time. Red indicates a positive correlation, blue indicates a negative correlation, and transparency represents a change in the $p$ value; the greater the $p$ value is, the greater the line transparency. Each dot represents one donor. Data were analyzed using unpaired, two-tailed $t$-tests (ns, $p>0.05$ ). Error bars represent the mean and SD. RC, recovered children; HC, healthy control; WAC, weeks after confirmation; S, spike; N, nucleocapsid.

There was no significant difference in the activities of serum-specific antibodies and NAbs among groups of different ages (Figure 1C,D). In addition, NAb titers showed a correlation with anti-S IgG levels $(p=0.6743, p<0.0001)$ but no significant correlation with other antibodies. Similar to the dynamics of anti-S and anti-N specific antibody levels, the neutralizing activity of plasma antibodies showed a negative correlation with weeks since diagnosis confirmation, decreasing gradually over time (Figure 1E). Collectively, the results indicated that children with mild COVID-19 who fully recovered produced a specific antibody response to SARS-CoV-2. Despite a rapid decline in IgM antibody levels, IgG antibodies and plasma neutralizing activity could be detected at least 6-8 months after diagnosis. Additionally, the level of $S$ protein-specific antibodies remained higher than that of N protein-specific antibodies (Figure 1A).

\subsection{The Immune Response Returns to Homeostasis in Recovered Children at 8 Months}

We also counted and analyzed white blood cells (WBCs), neutrophils, and lymphocytes in the plasma during the infection and recovery phases. The percentages of these cells were within normal limits at the follow-up visit approximately $6-8$ months after diagnosis 
confirmation. No significant lymphocytopenia of the investigated children was observed during the acute infection period (Figure 2A). In addition, we collected PBMCs and applied an 11-color flow cytometry panel (Supplementary Figure S2A), and the PBMCs were divided into seven cell types (Figure 2B). We further classified the two groups of children and projected the data on $\mathrm{tSNE}$ maps according to different age groups (Supplementary Figure S2B,C). The distribution of immune cells was similar across the three age groups in recovered or healthy children, but was different between these two populations. To further quantify this difference, we performed absolute quantification of immune cells in the samples. There were no differences in T cells (CD14-CD56-CD3 ${ }^{+}$) among PBMCs between healthy children and recovery phase individuals. Further analysis of $\mathrm{CD}^{+} \mathrm{T}$ cells showed that there was no significant difference in the magnitude or frequency of $\mathrm{CD}^{+}$or $\mathrm{CD}^{+} \mathrm{T}$ cells or in the $\mathrm{CD}^{+} / \mathrm{CD}^{+}$ratio (Figure $2 \mathrm{C}-\mathrm{F}$ ). Further analysis showed that there was a significant difference in the proportion of $\mathrm{B}$ cells (CD3-CD19 ${ }^{+}$) between healthy and recovered children in the lower age groups (0-4 and 5-9), with a lower level in infected children, while no significant difference was observed in the 10-14-year-old group (Figure 2G). In brief, except for B cells in 0-to-9-year-old children, no significant lymphopenia was observed in recovered children, and the number of adaptive immune cells in the blood of recovered patients returned to homeostasis 6-8 months after acute infection.

A
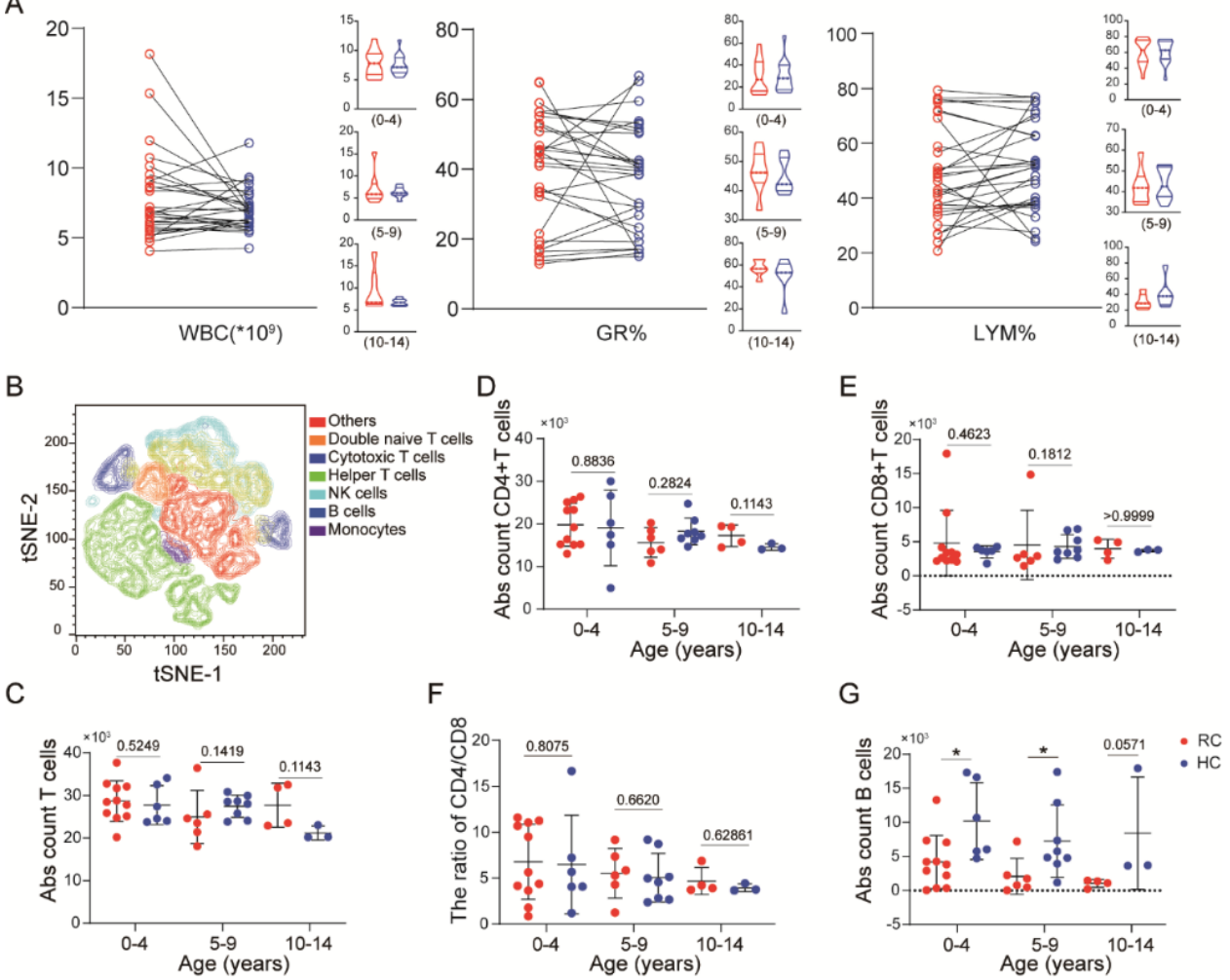

Figure 2. The immune response returns to homeostasis in children with mild COVID-19 at 8 months: (A) Changes in white blood cells (WBC), neutrophils and lymphocytes percentages after acute infection in children. (B) The tSNE plots shows the clustering of PBMCs. (C-E) The absolute counts of $\mathrm{CD}^{+}(\mathbf{C}), \mathrm{CD}^{+}(\mathrm{D})$, and $\mathrm{CD}^{+} \mathrm{T}$ cells $(\mathrm{E})$ in recovered and healthy children. (F) The ratio of the $\mathrm{CD} 4^{+} / \mathrm{CD}^{+}$cell population among different age groups. (G) The absolute counts of $\mathrm{CD} 19^{+} \mathrm{B}$ cells in recovered and healthy children. Each dot represents one donor. Data were analyzed using unpaired, two-tailed $t$-tests, ${ }^{*} p<0.05$. Error bars represent the mean and SD. RC, recovered children; $\mathrm{HC}$, healthy control; $\mathrm{S}$, spike; $\mathrm{N}$, nucleocapsid.

\subsection{SARS-CoV-2-Specific Memory T Cells Could Be Detected in Recovered Children}

We next investigated whether immune memory $\mathrm{T}$ cells exist in the peripheral blood of recovered children. $\mathrm{CD}^{+} \mathrm{T}$ cell and $\mathrm{CD}^{+} \mathrm{T}$ cell populations were divided into naive 
(CD45RA+CD27+CCR7+), central memory (CD45RA-CCR7+ (CM)), effector memory (CD45RA-CCR7- (EM)), and effector memory CD45RA+ (EMRA) (CD45RA+CCR7-) T cells. Both $\mathrm{CD}^{+}$and $\mathrm{CD}^{+} \mathrm{T}$ cell levels showed a significant increase in central memory $(\mathrm{Tcm})$ and effector memory (Tem) cell proportions in recovered children in the 0-to-4-yearold groups. However, in the 5-to-9-year-old groups, no significant differences in memory cell levels were found. Furthermore, the frequencies of Temra cells among CD4 ${ }^{+}$cells and of Tcm cells among $\mathrm{CD}^{+}$cells were increased in the 10-to-14-year-old group (Figure 3A,B). In addition, no difference in the proportion of naive $\mathrm{T}$ and memory $\mathrm{T}$ cell subtypes was discovered in children of different ages recovered from mild COVID-19 (Supplementary Figure S2D).

A
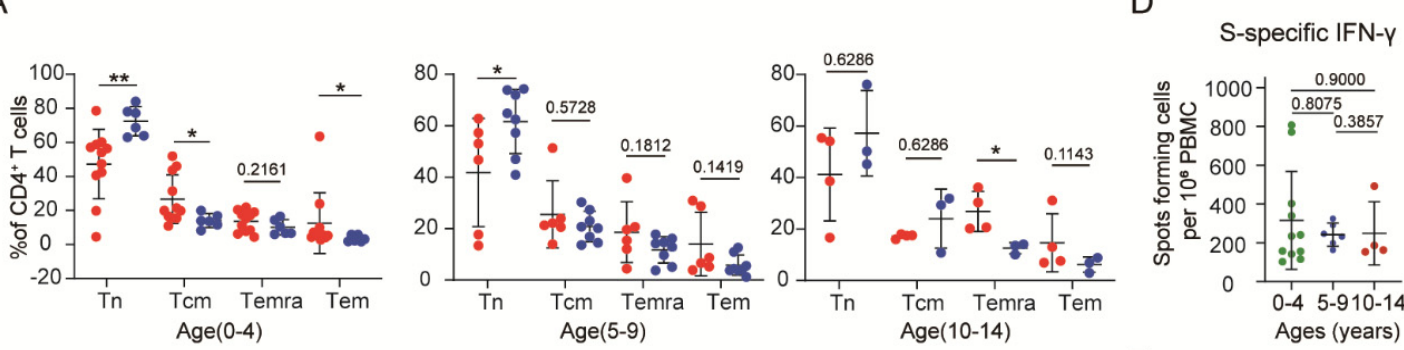

B
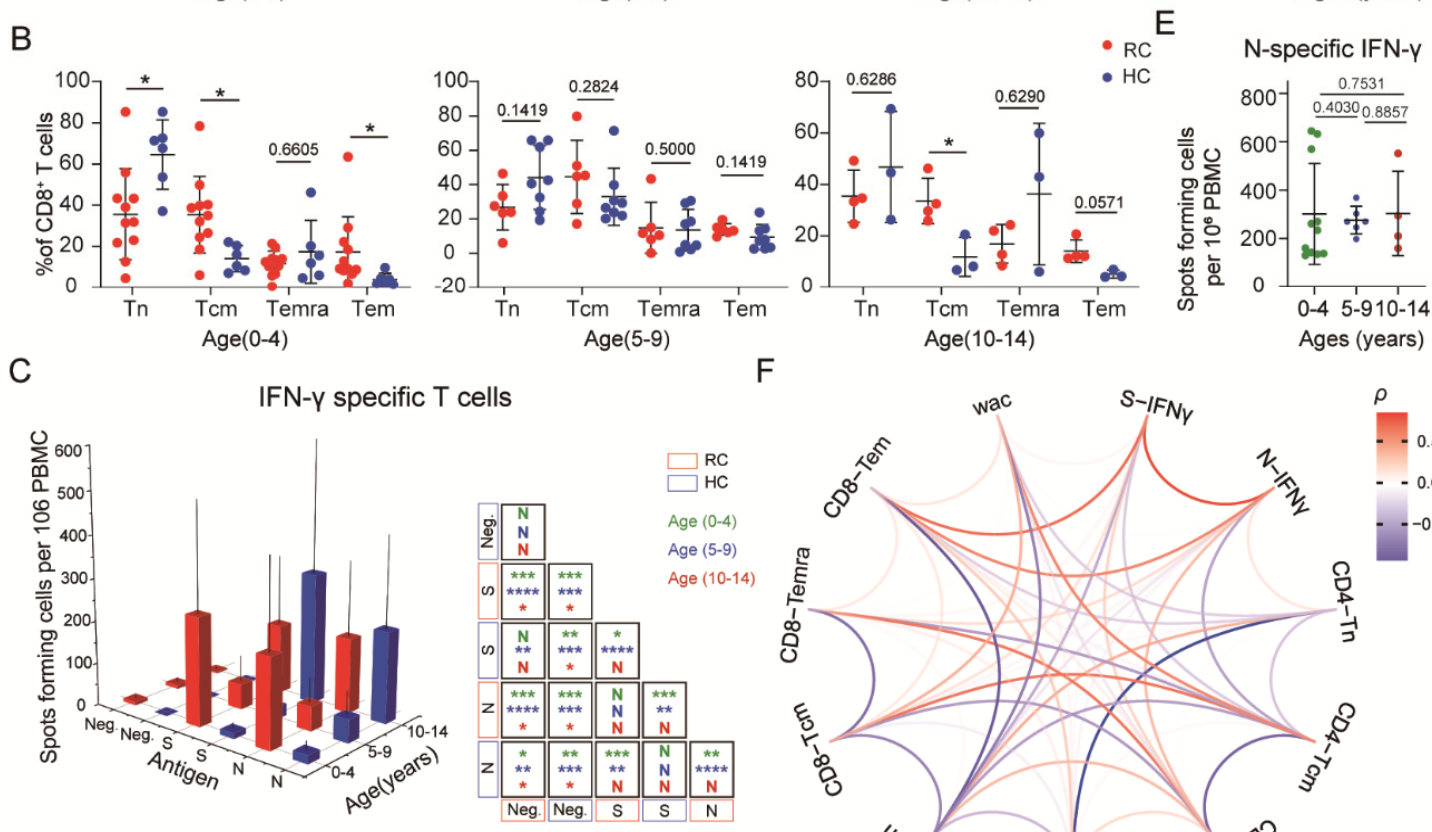

F

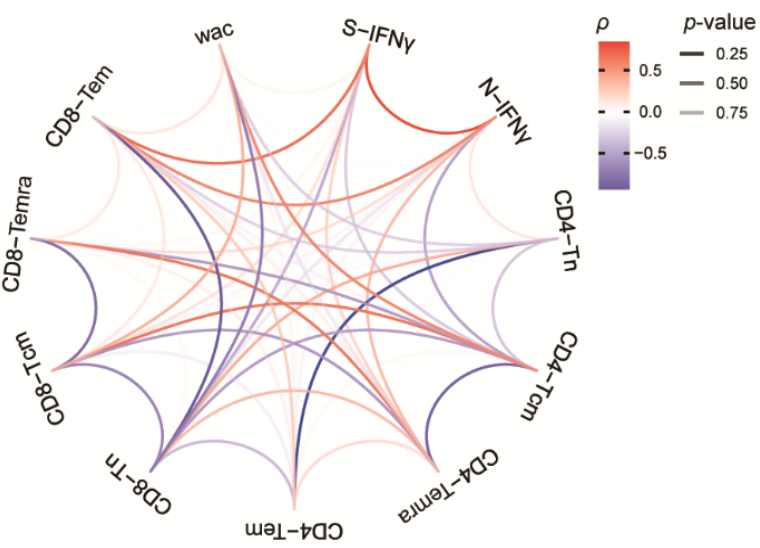

Figure 3. SARS-CoV-2-specific memory $\mathrm{T}$ cells were detected in children with mild COVID-19: (A) Comparisons of the frequency of helper T cell immune memory subsets in different age groups. (B) Comparisons of the frequencies of cytotoxic $\mathrm{T}$ cell immune memory subsets in different age groups. (C) Spike- and nucleocapsid-specific IFN- $\gamma$ memory T cell counts in recovered and healthy children. (D,E) Comparisons of spike- and nucleocapsid-specific IFN- $\gamma$ memory $\mathrm{T}$ cell counts by age category in recovered and healthy children. (F) Correlations among the frequencies of different memory T cell subsets, WAC and IFN- $\gamma$ responses. Red indicates a positive correlation, blue indicates a negative correlation, and transparency represents a change in the $p$ value; the greater the $p$-value is, the greater the line transparency. Each dot represents one donor. Data were analyzed using unpaired, two-tailed $t$-tests (ns, $p>0.05,{ }^{*} p<0.05,{ }^{* *} p<0.01$, and ${ }^{* * *} p<0.001$, and ${ }^{* * *} p<0.0001$ ). Error bars represent the mean and SD. RC, recovered children; HC, healthy control; WAC, weeks after confirmation; S, spike; N, nucleocapsid. 
To validate SARS-CoV-2-specific memory T cell immunity in COVID-19 convalescent children, we synthesized $\mathrm{S}$ and $\mathrm{N}$ protein to stimulate PBMCs. We found that the expression of IFN- $\gamma$ in T cells from recovered children was significantly increased after stimulation with the $\mathrm{S}$ or $\mathrm{N}$ protein compared with that in the control cells. In the 0-4-year-old and 5-9-year-old age groups, the response of healthy children was much lower than that of recovered children, yet there was no such difference in the 10-14-year-old age group. We also found a low-intensity response to $\mathrm{S}$ or $\mathrm{N}$ protein in nonexposed individuals, which reveals cross-reactivity with other common circulating coronaviruses (Figure 3C). No difference was observed in the response to $\mathrm{S}$ or $\mathrm{N}$ protein. Taken together, these data indicated that memory $\mathrm{T}$ cells specific for the $\mathrm{S}$ or $\mathrm{N}$ protein were generated and sustained in the peripheral blood of COVID-19 convalescent children, with no significant difference in IFN- $\gamma$ response degree against second exposure among different ages (Figure 3D,E).

To examine interrelations among the immune memory compartments and associations between the memory cell levels and COVID-19 recovery time, we performed comprehensive sets of correlation analyses. We observed a strong positive correlation between $\mathrm{S} / \mathrm{N}$-specific IFN- $\gamma$ secretion and $\mathrm{CD}^{+}$Tem cells but a negative correlation with $\mathrm{CD} 8^{+} \mathrm{Tn}$ and $\mathrm{CD} 4^{+}$ $\mathrm{Tcm}$ cells. Additionally, the frequencies of $\mathrm{CD} 4^{+} \mathrm{Tn}$ and $\mathrm{CD} 8^{+} \mathrm{Tn}$ cells were decreased over time after diagnosis confirmation, yet stabilization of total $\mathrm{CD}^{+} \mathrm{T}$ cells was observed in recovered children, suggestive of depleted naive $T$ cells gradually being replaced by memory $\mathrm{T}$ cells. Indeed, we observed a positive correlation between memory $\mathrm{T}$ cell frequencies and weeks after diagnosis confirmation, especially for $\mathrm{CD} 4^{+} \mathrm{Tcm}$ and $\mathrm{CD} 8^{+}$ Tcm cells (Figure 3F).

\subsection{SARS-CoV-2-Specific Memory B Cells Were Less Responsive in Recovered Children}

Memory B cell subpopulations were also detected in the recovered children. We observed that there were no significant differences in memory B cell $\left(\mathrm{CD} 19^{+} \mathrm{CD} 27^{+}\right)$frequency between recovered and healthy children at any age (Figure $4 \mathrm{~A}$ ).

To identify whether SARS-CoV-2-specific memory B cells exist, we used different fluorescently labeled IgG, IgM, and IgA probes to detect $B$ cells responsive to $S$ or $N$ protein stimulation. Unlike the memory $\mathrm{T}$ cell response, $\mathrm{IgG}^{+}$-specific memory B cells in SARSCoV-2-unexposed individuals were rare (S:1/21; N:2/21). Compared with these children, children from the recovered group showed higher specific memory $B$ cell frequencies. The response rates for $\mathrm{S}$ protein in the 0 -to-4, 5-to-9, and 10-to-14-year-old groups were $54.5 \%$, $66.7 \%$, and $100 \%$, respectively. For the $\mathrm{N}$ protein, the response rates were $27.2 \%, 50 \%$, and $100 \%$, respectively. Among the 0 -to-4-year-old group, there was no significant difference in the $\mathrm{IgG}^{+}$-specific memory B cell response between healthy and recovered children. The Sspecific memory B cells of recovered children were significantly more abundant than those of healthy donors in the 5-to-9-year-old groups. Especially in the 10-to-14-year-old groups, both S- and N-specific memory B cells of recovered children were abundant. Unexpectedly, we found a robust $\mathrm{IgM}^{+}$memory B cell response among children who recovered from COVID-19 in all age groups, while Ig $\mathrm{A}^{+}$responses occurred in the $0-4$-year-old and 10-14year-old age group. Meanwhile, there was no significant difference between the $\operatorname{IgM}^{+}$and $\mathrm{IgA}^{+}$memory $\mathrm{B}$ cell response to the $\mathrm{S}$ or $\mathrm{N}$ protein, while $\mathrm{IgG}^{+}$memory $\mathrm{B}$ cells responded more strongly to the S protein (Figure $4 \mathrm{~B}, \mathrm{C}$, Supplementary Figure S3A). Overall, the number of S-specific IgG $\mathrm{Ig}^{+}$memory B cells that could respond to the specific antigen of SARS$\mathrm{CoV}-2$ increased with age while that did not find in $\mathrm{IgM}^{+}$and $\mathrm{IgA}^{+}$responses. (Figure $4 \mathrm{D}-\mathrm{G}$, Supplementary Figure S3B,C). The secondary response to antibodies indicated the presence of SARS-CoV-2-specific memory B cells in recovered children.

We also analyzed the relationships among antibody secretion, the memory B cell level, and the weeks after diagnosis confirmation. Intriguingly, we found that the IgG response was negatively correlated with the weeks after diagnosis confirmation and the memory B cell level, while the IgM response showed a positive correlation. Furthermore, the S-specific IgG response was negatively correlated with the S-specific IgM response 
(Figure $4 \mathrm{H}$ ). In summary, the results showed a more robust $\operatorname{IgM}^{+}$memory B cell response than $\mathrm{IgG}^{+}$response, and the number of S-specific $\mathrm{IgG}^{+}$memory B cells increased with age.

A

C
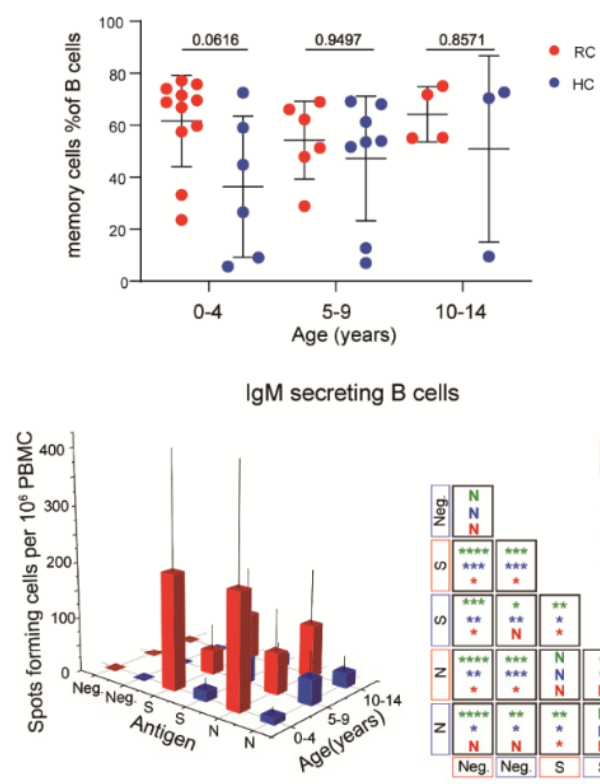

$\mathrm{F}$

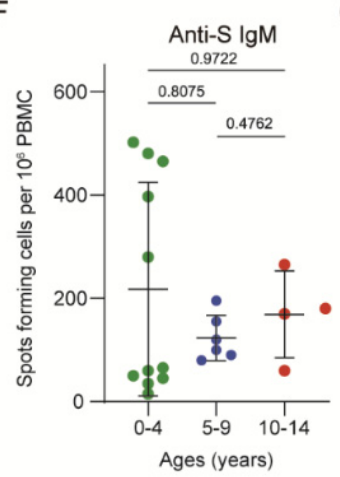

B

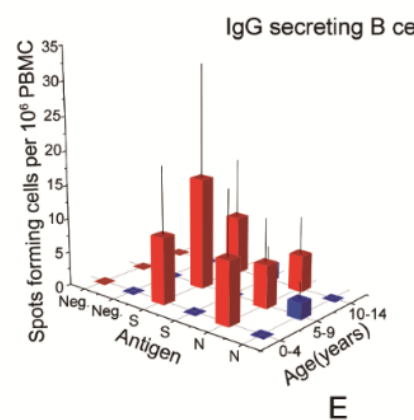

E
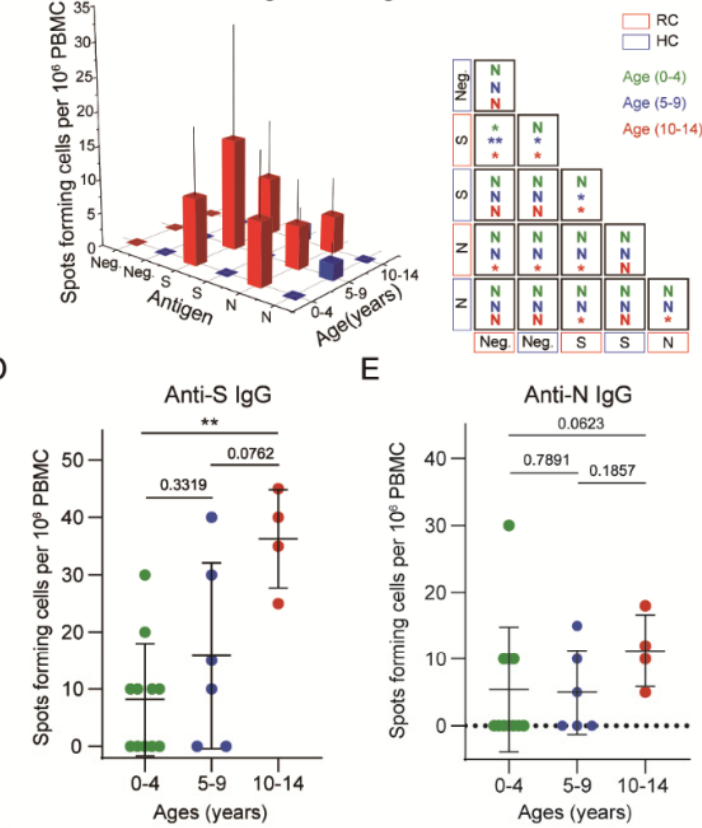

$\mathrm{H}$
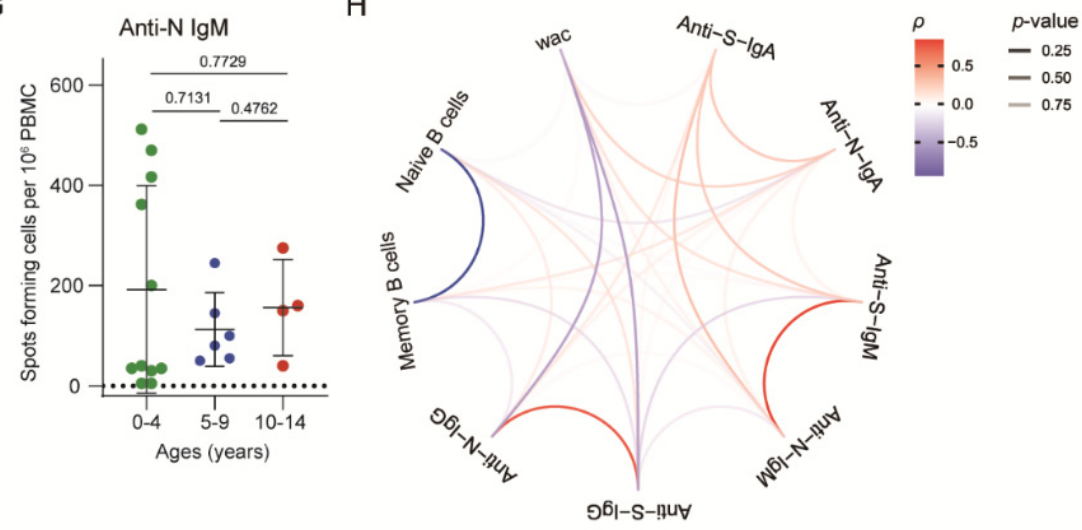

Figure 4. SARS-CoV-2-specific memory B cells show a weak response in children with mild COVID19: (A) Comparisons of the memory B cell frequency of recovered and healthy children in different age groups. (B,C) Spike- and nucleocapsid-specific $\mathrm{IgG}^{+}, \mathrm{IgM}^{+}$and memory B cell counts in recovered and healthy children. (D-G) Comparisons of spike- and nucleocapsid-specific $\mathrm{IgG}^{+}, \mathrm{IgM}^{+}$memory $B$ cell counts by age category in recovered and healthy children. Each dot represents one donor. (H) Comparisons of spike- and nucleocapsid-specific antibody memory B cell numbers by age category in recovered and healthy children. Red indicates a positive correlation, blue indicates a negative correlation, and transparency represents a change in the $p$ value; the greater the $p$ value is, the greater the line transparency. Data were analyzed using unpaired, two-tailed t-tests (ns, $p>0.05$, ${ }^{*} p<0.05,{ }^{* *} p<0.01$, and ${ }^{* * *} p<0.001$, and $\left.{ }^{* * *} p<0.0001\right)$. Error bars represent the mean and SD. RC, recovered children; $\mathrm{HC}$, healthy control; WAC, weeks after confirmation; S, spike; N, nucleocapsid.

\section{Discussion}

The severity of clinical symptoms and prognosis of children infected with SARS-CoV-2 have always been the focus of research on SARS-CoV-2 infection and immunization [16,17]. Insight into whether children can acquire immune memory post-infection and the extent to which they can recover during recovery is crucial to evaluating the value of childhood passive immunization and improving treatment options for children [18,19]. Clinical mani- 
festations showed that although some mild or asymptomatic children present respiratory symptoms accompanied by increased inflammatory markers in the acute infection phase, most of them recover within 6-8 months. Unfortunately, although the recovered patients avoided fatigue, mental stress, and other conditions to prevent secondary infection, and maintained oxygen inhalation and carried out lung function recovery training, it was found that the lesions of some patients were not completely recovered and their lung function failed to reach a healthy level during the lung function test. In contrast with healthy children, we determined that there was still a certain level of antibody in serum from recovered subjects. Moreover, the immune system reattains healthy status, forming immune memory and producing an enhanced memory response to secondary SARS-CoV-2 antigen stimulation.

These results extend studies on immune memory in humans after coinfection with SARS-CoV-2 infection, demonstrating that immune memory is also present in children [20,21]. In addition, our findings suggested that childhood immunity is not the same as adult immunity [22]. In children who recovered, antibody levels increased faster and more markedly over time, while in adults, they declined more slowly [23]. We also found higher IgM cutoff values in systematic serological tests of children, which is consistent with the conclusion of $\mathrm{W}$. Chung et al. [22]. This finding could mean that IgM, as a relatively sensitive antibody, is better able to protect against the virus once it invades, leading to a higher proportion of mild disease in children.

In addition to the differences in antibody protection, there were also significant differences in cellular immunity. In combination with the work of Nimesh Gupta et al., we found that the response of IFN- $\gamma$-secreting $\mathrm{CD}^{+}$and $\mathrm{CD}^{+} \mathrm{T}$ cells to viral structural proteins in recovered children was significantly less than that in adults [24-26]. Furthermore, Shane Crotty et al. identified that adult memory B cells mainly secrete IgG-subtype antibodies in response to SARS-CoV-2 [27,28]. However, our study showed a higher proportion of IgM than IgG to SARS-CoV-2 S or N protein stimulation in children; that is, in contrast to memory B cells producing IgG, the child immune response tended to consist of $\operatorname{IgM}^{+}$ memory $\mathrm{B}$ cells differentiating and proliferating more rapidly in response to SARS-CoV-2 invasion, suggesting that characteristics of memory B cells in children are different from those in adults. Antonio Di Sabatino et al. reported that the loss of $\operatorname{IgM}^{+}$memory B cells in adults is usually indicative of a poor prognosis in SARS-CoV-2 patients, which also provides evidence to explain the milder clinical outcome of SARS-CoV-2 infection in children than in adults [29-31].

Compared with asymptomatic or mild patients, severe children patients exhibited more obvious symptoms of peripheral blood lymphocytopenia and increased inflammatory factor levels $[32,33]$. Therefore, the study of children has mainly concentrated on severe disease and its complications, with scant reports specifically focused on asymptomatic or mildly symptomatic patients, especially for the recovery of bodily function and immune memory. Limited by the investigation population, our study recruited only asymptomatic or mildly infected children and found no history of allergic diseases such as asthma or dermatitis. Children with these diseases often carry auto-antibodies, which may worsen an illness after infection with SARS-CoV-2, or even evolve into multiple systems inflammatory syndrome in children (MIS-C) [33,34]. Similarly, IgG antibody level was positively correlated with the severity of the disease, which was also confirmed by our results. In mild patients who recovered from the disease, IgG disappeared for a period of time after recovery, and memory B cells replaced the antibodies in plasma to protect the body [35,36]. In general, this study showed that lung function in infants takes more time to recover, and we also proved that the immune system in children returned to normal 6-8 months after SARS-CoV-2 infection and established SARS-CoV-2-specific memory $\mathrm{T}$ cell and $\mathrm{B}$ cell responses. 
From our results, it was confirmed that children diagnosed with mild symptoms have sustained antibody responses after infection. Notably, they also produced T cell and B cell responses to the viral spike and nucleocapsid proteins, even though the response was less intense than that in adults [37]. In conclusion, our results suggest that children with mild symptoms can form systemic immune memory and prevent severe infection to some extent, thus contributing to the establishment of herd immunity.

Supplementary Materials: The following supporting information can be downloaded at: https: / / www.mdpi.com/article/10.3390/v14010085/s1, Figure S1: SARS-CoV-2-specific IgM response in children with mild COVID-19 at 6-8 months after infection, Figure S2: Phenotype analysis of immune cells, Figure S3: SARS-CoV-2-specific IgA ${ }^{+}$memory B cells with mild COVID-19, Table S1: Age and sex statistics of experimental group samples, Table S2: Serological markers of serum samples from follow-up children, Table S3: Pulmonary function test values of recovered children at revisit.

Author Contributions: Conceptualization, J.L.; methodology, X.T. and Z.B.; resources, J.L.; data curation, X.T., Z.B. and Y.C.; writing-original draft preparation, X.T., Z.B. and J.L.; writing-review and editing, X.T., Z.B. and J.L.; suggestion, D.L. and H.L.; supervision, J.L. and W.L.; funding acquisition, W.L. and J.L. visualization, X.T., Z.B. and J.L. All authors have read and agreed to the published version of the manuscript.

Funding: This work was supported by the National Natural Science Foundation of China (32170143, 31970153, 3191101787). J.L. is supported by Youth Innovation Promotion Association of CAS (2019091).

Institutional Review Board Statement: The study was conducted in accordance with the Declaration of Helsinki, and approved by the Ethics Committee of Wuhan Children's Hospital and Wuhan Maternal and Child Health Hospital (protocol code WHCH2020003 and 4 February 2020 of approval).

Informed Consent Statement: Informed consent was obtained from all subjects involved in the study.

Data Availability Statement: Further information and requests for resources and reagents should be directed to J.L.

Conflicts of Interest: The authors declare no conflict of interest. The funders had no role in the design of the study; in the collection, analyses, or interpretation of data; in the writing of the manuscript, or in the decision to publish the results.

\section{References}

1. Hui, D.S.; Azhar, E.I.; Madani, T.A.; Ntoumi, F.; Kock, R.; Dar, O.; Ippolito, G.; McHugh, T.D.; Memish, Z.A.; Drosten, C.; et al. The continuing 2019-nCoV epidemic threat of novel coronaviruses to global health-The latest 2019 novel coronavirus outbreak in Wuhan, China. Int. J. Infect. Dis. 2020, 91, 264-266. [CrossRef]

2. Zhu, N.; Zhang, D.; Wang, W.; Li, X.; Yang, B.; Song, J.; Zhao, X.; Huang, B.; Shi, W.; Lu, R.; et al. A Novel Coronavirus from Patients with Pneumonia in China, 2019. N. Engl. J. Med. 2020, 382, 727-733. [CrossRef]

3. Tian, X.; Jiang, W.; Zhang, H.; Lu, X.; Li, L.; Liu, W.; Li, J. Persistence of the SARS-CoV-2 Antibody Response in Asymptomatic Patients in Correctional Facilities. Front. Microbiol. 2021, 12, 789374. [CrossRef] [PubMed]

4. Sekine, T.; Perez-Potti, A.; Rivera-Ballesteros, O.; Strålin, K.; Gorin, J.B.; Olsson, A.; Llewellyn-Lacey, S.; Kamal, H.; Bogdanovic, G.; Muschiol, S.; et al. Robust T Cell Immunity in Convalescent Individuals with Asymptomatic or Mild COVID-19. Cell 2020, 183, 158-168.e14. [CrossRef] [PubMed]

5. Zhang, F.; Gan, R.; Zhen, Z.; Hu, X.; Li, X.; Zhou, F.; Liu, Y.; Chen, C.; Xie, S.; Zhang, B.; et al. Adaptive immune responses to SARS-CoV-2 infection in severe versus mild individuals. Signal Transduct. Target. Ther. 2020, 5, 156. [CrossRef] [PubMed]

6. Rodda, L.B.; Netland, J.; Shehata, L.; Pruner, K.B.; Morawski, P.A.; Thouvenel, C.D.; Takehara, K.K.; Eggenberger, J.; Hemann, E.A.; Waterman, H.R. Functional SARS-CoV-2-specific immune memory persists after mild COVID-19. Cell 2021, 184, 169-183.e17. [CrossRef] [PubMed]

7. Yao, L.; Wang, G.L.; Shen, Y.; Wang, Z.Y.; Zhan, B.D.; Duan, L.J.; Lu, B.; Shi, C.; Gao, Y.M.; Peng, H.H.; et al. Persistence of Antibody and Cellular Immune Responses in COVID-19 patients over Nine Months after Infection. J. Infect. Dis. 2021.

8. Tavukcuoglu, E.; Horzum, U.; Cagkan Inkaya, A.; Unal, S.; Esendagli, G. Functional responsiveness of memory T cells from COVID-19 patients. Cell. Immunol. 2021, 365, 104363. [CrossRef] [PubMed]

9. Ni, L.; Ye, F.; Cheng, M.L.; Feng, Y.; Deng, Y.Q.; Zhao, H.; Wei, P.; Ge, J.; Gou, M.; Li, X.; et al. Detection of SARS-CoV-2-Specific Humoral and Cellular Immunity in COVID-19 Convalescent Individuals. Immunity 2020, 52, 971-977.e3. [CrossRef]

10. Tian, X.; Liu, L.; Jiang, W.; Zhang, H.; Liu, W.; Li, J. Potent and Persistent Antibody Response in COVID-19 Recovered Patients. Front. Immunol. 2021, 12, 1986. [CrossRef] [PubMed] 
11. Ludvigsson, J.F. Systematic review of COVID-19 in children shows milder cases and a better prognosis than adults. Acta Paediatr. 2020, 109, 1088-1095. [CrossRef]

12. Parri, N.; Lenge, M.; Buonsenso, D. Children with COVID-19 in Pediatric Emergency Departments in Italy. N. Engl. J. Med. 2020, 383, 187-190. [CrossRef] [PubMed]

13. Su, L.; Ma, X.; Yu, H.; Zhang, Z.; Bian, P.; Han, Y.; Sun, J.; Liu, Y.; Yang, C.; Geng, J.; et al. The different clinical characteristics of corona virus disease cases between children and their families in China-The character of children with COVID-19. Emerg. Microbes Infect. 2020, 9, 707-713. [CrossRef]

14. Qiu, H.; Wu, J.; Hong, L.; Luo, Y.; Song, Q.; Chen, D. Clinical and epidemiological features of 36 children with coronavirus disease 2019 (COVID-19) in Zhejiang, China: An observational cohort study. Lancet Infect. Dis. 2020, 20, 689-696. [CrossRef]

15. Ou, X.; Liu, Y.; Lei, X.; Li, P.; Mi, D.; Ren, L.; Guo, L.; Guo, R.; Chen, T.; Hu, J. Characterization of spike glycoprotein of SARS-CoV-2 on virus entry and its immune cross-reactivity with SARS-CoV. Nat. Commun. 2020, 11, 1620. [CrossRef]

16. García, L.F. Immune response, inflammation, and the clinical spectrum of COVID-19. Front. Immunol. 2020, 11, 1441. [CrossRef]

17. Sherina, N.; Piralla, A.; Du, L.; Wan, H.; Kumagai-Braesch, M.; Andréll, J.; Braesch-Andersen, S.; Cassaniti, I.; Percivalle, E.; Sarasini, A. Persistence of SARS-CoV-2-specific B and T cell responses in convalescent COVID-19 patients 6-8 months after the infection. Med 2021, 2, 281-295.e4. [CrossRef] [PubMed]

18. Feldstein, L.R.; Rose, E.B.; Horwitz, S.M.; Collins, J.P.; Newhams, M.M.; Son, M.B.F.; Newburger, J.W.; Kleinman, L.C.; Heidemann, S.M.; Martin, A.A. Multisystem inflammatory syndrome in US children and adolescents. N. Engl. J. Med. 2020, 383, 334-346. [CrossRef]

19. Cunha, L.L.; Perazzio, S.F.; Azzi, J.; Cravedi, P.; Riella, L.V. Remodeling of the immune response with aging: Immunosenescence and its potential impact on COVID-19 immune response. Front. Immunol. 2020, 11, 1748. [CrossRef] [PubMed]

20. Elahi, S. Neonatal and Children's Immune System and COVID-19: Biased Immune Tolerance versus Resistance Strategy. J. Immunol. 2020, 205, 1990-1997. [CrossRef]

21. Felsenstein, S.; Hedrich, C.M. SARS-CoV-2 infections in children and young people. Clin. Immunol. 2020, 220, 108588. [CrossRef]

22. Selva, K.J.; van de Sandt, C.E.; Lemke, M.M.; Lee, C.Y.; Shoffner, S.K.; Chua, B.Y.; Davis, S.K.; Nguyen, T.H.; Rowntree, L.C.; Hensen, L. Systems serology detects functionally distinct coronavirus antibody features in children and elderly. Nat. Commun. 2021, 12, 2037. [CrossRef]

23. Wong, L.S.Y.; Loo, E.X.L.; Kang, A.Y.H.; Lau, H.X.; Tambyah, P.A.; Tham, E.H. Age-related differences in immunological responses to SARS-CoV-2. J. Allergy Clin. Immunol. Pract. 2020, 8, 3251-3258. [CrossRef]

24. Ansari, A.; Arya, R.; Sachan, S.; Jha, S.N.; Kalia, A.; Lall, A.; Sette, A.; Grifoni, A.; Weiskopf, D.; Coshic, P. Immune Memory in Mild COVID-19 Patients and Unexposed Donors Reveals Persistent T Cell Responses After SARS-CoV-2 Infection. Front. Immunol. 2021, 12, 749. [CrossRef] [PubMed]

25. Giménez, E.; Albert, E.; Torres, I.; Remigia, M.J.; Alcaraz, M.J.; Galindo, M.J.; Blasco, M.L.; Solano, C.; Forner, M.J.; Redón, J. SARS-CoV-2-reactive interferon- $\gamma$-producing $\mathrm{CD}^{+} \mathrm{T}$ cells in patients hospitalized with coronavirus disease 2019. J. Med. Virol. 2021, 93, 375-382. [CrossRef] [PubMed]

26. Pierce, C.A.; Preston-Hurlburt, P.; Dai, Y.; Aschner, C.B.; Cheshenko, N.; Galen, B.; Garforth, S.J.; Herrera, N.G.; Jangra, R.K.; Morano, N.C.; et al. Immune responses to SARS-CoV-2 infection in hospitalized pediatric and adult patients. Sci. Transl. Med. 2020, 12. [CrossRef] [PubMed]

27. Anand, S.P.; Prévost, J.; Nayrac, M.; Beaudoin-Bussières, G.; Benlarbi, M.; Gasser, R.; Brassard, N.; Laumaea, A.; Gong, S.Y.; Bourassa, C. Longitudinal analysis of humoral immunity against SARS-CoV-2 Spike in convalescent individuals up to 8 months post-symptom onset. Cell Rep. Med. 2021, 2, 100290. [CrossRef]

28. Dan, J.M.; Mateus, J.; Kato, Y.; Hastie, K.M.; Yu, E.D.; Faliti, C.E.; Grifoni, A.; Ramirez, S.I.; Haupt, S.; Frazier, A. Immunological memory to SARS-CoV-2 assessed for up to 8 months after infection. Science 2021, 371, eabf4063. [CrossRef]

29. Lenti, M.V.; Aronico, N.; Pellegrino, I.; Boveri, E.; Giuffrida, P.; de Andreis, F.B.; Morbini, P.; Vanelli, L.; Pasini, A.; Ubezio, C. Depletion of circulating IgM memory B cells predicts unfavourable outcome in COVID-19. Sci. Rep. 2020, 10, 20836. [CrossRef]

30. Abdel-Azim, H.; Elshoury, A.; Mahadeo, K.M.; Parkman, R.; Kapoor, N. Humoral immune reconstitution kinetics after allogeneic hematopoietic stem cell transplantation in children: A maturation block of IgM memory B cells may lead to impaired antibody immune reconstitution. Biol. Blood Marrow Transplant. 2017, 23, 1437-1446. [CrossRef]

31. Capolunghi, F.; Rosado, M.M.; Sinibaldi, M.; Aranburu, A.; Carsetti, R. Why do we need IgM memory B cells? Immunol. Lett. 2013, 152, 114-120. [CrossRef] [PubMed]

32. Ramaswamy, A.; Brodsky, N.N.; Sumida, T.S.; Comi, M.; Asashima, H.; Hoehn, K.B.; Li, N.; Liu, Y.; Shah, A.; Ravindra, N.G. Immune dysregulation and autoreactivity correlate with disease severity in SARS-CoV-2-associated multisystem inflammatory syndrome in children. Immunity 2021, 54, 1083-1095.e7. [CrossRef]

33. Consiglio, C.R.; Cotugno, N.; Sardh, F.; Pou, C.; Amodio, D.; Rodriguez, L.; Tan, Z.; Zicari, S.; Ruggiero, A.; Pascucci, G.R. The immunology of multisystem inflammatory syndrome in children with COVID-19. Cell 2020, 183, 968-981.e7. [CrossRef]

34. Jarlhelt, I.; Nielsen, S.K.; Jahn, C.X.H.; Hansen, C.B.; Pérez-Alós, L.; Rosbjerg, A.; Bayarri-Olmos, R.; Skjoedt, M.-O.; Garred, P. SARS-CoV-2 Antibodies Mediate Complement and Cellular Driven Inflammation. Front. Immunol. 2021, 12, 767981. [CrossRef] [PubMed] 
35. Wu, Q.; Hou, X.; Li, H.; Guo, J.; Li, Y.; Yang, F.; Zhang, Y.; Xie, Y.; Li, L. A follow-up study of respiratory and physical function after discharge in patients with redetectable positive SARS-CoV-2 nucleic acid results following recovery from COVID-19. Int. J. Infect. Dis. 2021, 107, 5-11. [CrossRef]

36. Strumiliene, E.; Zeleckiene, I.; Bliudzius, R.; Samuilis, A.; Zvirblis, T.; Zablockiene, B.; Strumila, A.; Gruslys, V.; Malinauskiene, L.; Kasiulevicius, V. Follow-up analysis of pulmonary function, exercise capacity, radiological changes, and quality of life two months after recovery from SARS-CoV-2 pneumonia. Medicina 2021, 57, 568. [CrossRef] [PubMed]

37. Carsetti, R.; Zaffina, S.; Piano Mortari, E.; Terreri, S.; Corrente, F.; Capponi, C.; Palomba, P.; Mirabella, M.; Cascioli, S.; Palange, P. Different Innate and Adaptive Immune Responses to SARS-CoV-2 Infection of Asymptomatic, Mild, and Severe Cases. Front. Immunol. 2020, 11, 3365. [CrossRef] 